\title{
Envelop Insulation for Energy Efficient Smart Buildings in India
}

\author{
Jaya Goyal, Shankar S. Mantha, Vikas M. Phalle
}

\begin{abstract}
The building sector is amongst the largest energy consuming sector across the world. Within the building sector, about 75 percent of the total energy is consumed by the residential buildings. The energy sector is directly and indirectly associated with greenhouse gas emissions, since majority of energy sector is dependent on fossil fuels, which are primary source of emanation. Building energy requirements are comprised of need for lighting, air conditioning and other home appliances operations. Air conditioning requirement is derived from the climatic condition in which a building exists. The building components such as walls, roof and windows are exposed to solar radiation and outside air temperature. Heat is conducted from exterior environment into the interior of the building envelop through these channels, wherein majority (approx. 60\%) is conducted by walls and roof. Envelop insulation is considered as an efficient retrofitting measure to reduce heat gain from walls and roof, thereby need of air conditioning to remove that heat.
\end{abstract}

In this work, envelop insulation has been designed for the Indian residential buildings existing in the three climate zones of India, i.e. warm-humid, hot-dry and composite climate zones. Electricity saving potential in an insulated envelop and associated life cycle cost saving analysis is carried out considering the application of four commercial insulation materials namely, expanded polystyrene, fiberglass, polyurethane foam and extruded polystyrene. It was concluded that at the design temperature $25^{\circ} \mathrm{C}$, annual electricity saving potential in retrofitted wall per unit area varies from $9 \mathrm{kWh}$ to $16 \mathrm{kWh}$, whereas in case of roof it varies from $18 \mathrm{kWh}$ to $28 \mathrm{kWh}$ per unit area per year. Fiberglass is observed as the most cost effective insulation material, considering life cycle performance of the insulation material for all the climate zones.

Keywords : Building insulation, Climate zone, Electricity saving potential, Life cycle cost, Residential building.

\section{INTRODUCTION}

The domestic sector in India is second leading electricity consuming sector with the consumption of $24.4 \%$ of the total electricity generated [1]. This sector has seen significant rise over the years, from $9 \%(423 \mathrm{GWh})$ in the year 1947 to $24 \%(273550 \mathrm{GWh})$ in the year 2018. Approximately 75 percentage of total electricity generated is derived from coal based power plants. Coal is considered as the prime source of green-house gas (CO2) emission. Due to poor coal grade available in India and inefficient thermal power plants, about $0.82 \mathrm{~kg}$ of $\mathrm{CO} 2$ is emitted from 1 unit (1 $\mathrm{kWh}$ ) of electricity generation [1]. Thereby, for the Indian

Revised Manuscript Received on September 10, 2019.

Jaya Goyal, Mechanical Engineering Department, Veermata Jijabai Technological Institute, Mumbai, Maharashtra, India.

(Email: jayasingh2006@ gmail.com)

Shankar S. Mantha, Mechanical Engineering Department, Veermata Jijabai Technological Institute, Mumbai, Maharashtra, India.

(Email: ssmantha33@gmail.com)

Vikas M. Phalle, Mechanical Engineering Department, Veermata Jijabai Technological Institute, Mumbai, Maharashtra, India.

(Email: vmphalle@vjti.org.in) power sector electricity conservation is directly associated with reduction in significant carbon footprints. In India, appliances dispersion (specifically air conditioners) in the households is one of the principal driver for high electricity consumption in the domestic sector. Reference [2] indicates that air conditioners in India will be accountable for twothird of the increased green-house gas emissions. A positive and significant correlation has been observed between the usage of air conditioners and electricity consumption of Indian urban households in some of recent research studies [3-4]. Air conditioning is essential to remove external heat gain in the building envelop through the various channels such as external walls, roof and windows. Fig. 1 illustrates the heat gained in a building due to exposure of a household to the external environment [5].

It is evident from the Fig.1 that amongst various sources, majority (approx. 60\%) of heat is conducted by walls and roof. Envelop insulation is considered as an efficient retrofitting measure to reduce heat gain from walls and roof, thereby need of air conditioning to remove that heat. However, an effective insulation design is also essential for maximizing the technical and economic electricity saving potential. In general, with the increase of insulation thickness heat gain reduces, which subsequently reduces the need of air conditioning and hence electricity cost, but the associated insulation cost also increases with the insulation thickness.

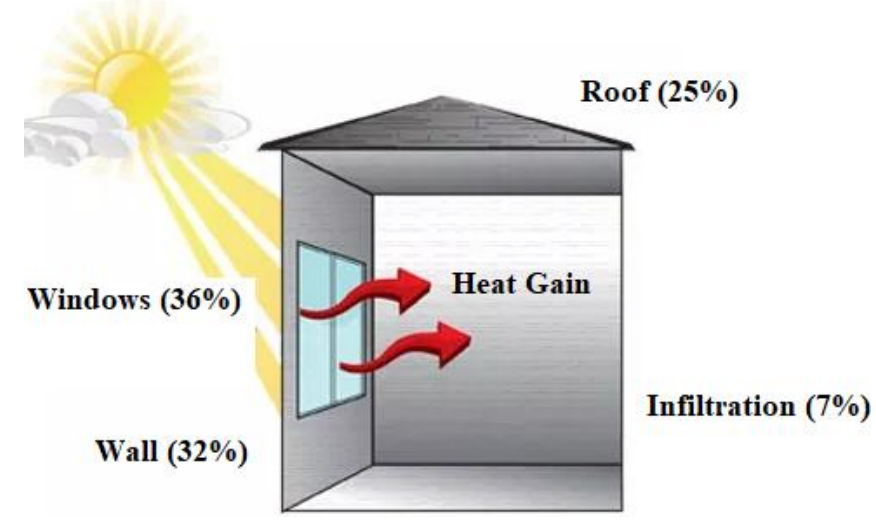

Fig. 1. Heat load components for a residential building envelop

Therefore, an optimum insulation thickness is required to maximize the technical and economic electricity saving potential. In this work, envelop insulation has been designed for the Indian residential buildings existing in the three 
climate zones of India, i.e. warm-humid, hot-dry and composite climate zones. Based on a market survey, most commonly used commercial insulation materials such as fiberglass, polyurethane foam, expanded polystyrene and extruded polystyrene have been used for comparative insulation design in three climatic regions.

\section{LITERATURE REVIEW}

In the literature review, life cycle cost based mathematical model was found as the most common methodology to derive optimal insulation thickness (OIT). Comakl and Yuksel derived the OIT for the three coldest cities in Turkey, based on the life cycle cost (LCC) analysis [6]. A mathematical model based on the heat transfer principle was developed. Life cycle cost of the energy saved was obtained using net worth of the energy saved in the lifetime of the insulation. It was observed that up to $12 \$ / \mathrm{m} 2$ can be saved by applying insulation to walls. Dombayc et al. determined the optimal insulation thickness for walls using LCC, considering the usage of different types of heating sources (natural gas, coal, LPG, electricity) and insulation materials (expanded polystyrene and rock wool) for the city Denizli, Turkey [7]. Results showed that OIT is minimum when coal is selected as the fuel source and expanded polystyrene is selected as insulation material. Investigation showed potential of $14 \$ / \mathrm{m} 2$ in wall insulation. Hasan used LCC analysis approach in obtaining optimal insulation configuration for different wall structures [8]. Shanmuga and Bhaskaran, obtained the OIT of walls for 5 cities in hot regions of India using three insulation materials (expanded polystyrene, polyurethane foam and PVC foam) [9]. To formulate the OIT, authors adopted P1-P2 method which is used to determine the present worth of the energy saving by providing insulation. Here P1 refers to life cycle energy derived from electricity cost, interest rate and analysis period. Whereas, $\mathrm{P} 2$ is the ratio of life cycle expenditure due to the additional capital cost incurred in insulation. Kumar and Suman conducted experimental performance analysis for various insulation materials [10]. 112 combinations of wall and roof with insulation materials were analysed with different R-values and U-factor, to obtain a suitable combination conforming the Energy Conservation Building Code (ECBC), India. Similarly, Tulsyan et al. [11] and Chedwal et al. [12] also identified the insulation materials and corresponding thickness for commercial buildings in India to meet the ECBC standards.

Literature review period between the year 2000 to till date shows that only 8 research studies are specifically dedicated in exploring the application of insulated envelops in India prompting the subject to be studied further for Indian climatic conditions. In the absence of energy conservation guidelines for the residential sector, an in-depth investigation and understanding of envelop insulation subject becomes more essential. The objective of the present work is to examine the performance of commonly used insulation materials for the residential buildings in the three climate zones of India and justify their suitability through an economic modelling approach.

\section{METHODOLOGY}

In this work, OIT design is based on the cooling energy required to remove the heat transferred through the walls and roof and associated cost of cooling. Heat gain through a thermal mass like wall and roof depends on the heat transfer coefficient (HTC) of the thermal mass and average temperature difference between exterior and interior of the building. Annual heat gain through the unit surface of a thermal mass (wall/roof) is given by following relation-

$$
E_{\text {year }}=86400 * C D D * U
$$

Where CDD is the cooling degree days (CDD) and $\mathrm{U}$ is the overall HTC of the thermal mass. The concept of CDD is used to quantify the cooling energy required which measures the deviation of day's average temperature from the envelop design temperature [13]. CDD varies with the location of a household and design temperature. A noninsulated wall/roof is constructed in three layers: internal plaster layer, brick layer (in case of wall)/ RCC (in case of roof) layer and external plaster layer. Overall HTC of noninsulated wall ( $U_{\text {wall }}$ )and roof ( $U_{\text {roof }}$ ) can be given by the following equations-

$$
\begin{gathered}
U_{\text {wall }}=\frac{1}{R_{w, t}}=\frac{1}{\left(R_{i}+R_{\text {wall }}+R_{o}\right)}=\frac{1}{\left(\frac{1}{h_{i}}+\frac{x_{i, c p}}{K_{c p}}+\frac{x_{b r k}}{K_{b r k}}+\frac{x_{e, c p}}{K_{c p}}+\frac{1}{h_{o}}\right)} \\
U_{\text {roof }}=\frac{1}{R_{r, t}}=\frac{1}{\left(R_{i}+R_{\text {roof }}+R_{o}\right)}=\frac{1}{\left(\frac{1}{h_{i}}+\frac{x_{i, c p}}{K_{c p}}+\frac{x_{r c c}}{K_{r c c}}+\frac{x_{e, c p}}{K_{c p}}+\frac{1}{h_{o}}\right)}
\end{gathered}
$$

Where symbols used in the equations are as follows: $R_{w, t}$ and $R_{r, t}$ are the total thermal resistance offered by the wall and roof; $R_{i}$ and $R_{o}$ are the convective thermal resistance of the internal and external surface of the thermal mass, which is reciprocal of their convective heat transfer coefficients $h_{i}$ and $h_{o}$ respectively; $x_{i, c p}$ and $x_{e, c p}$ are the thickness of internal and external cement plaster layers; $x_{b r k}$ and $x_{r c c}$ are the thickness of brick layer and RCC layer; $K_{c p}, K_{b r k}$ and $K_{r c c}$ are the thermal conductivities of cement plaster, brick and RCC. The required cooling energy per annum to eradicate the heat gain from the per unit area of non-insulated wall and roof can be estimated using the following equations-

$$
\begin{aligned}
& E_{\text {year }, \text { wall }}=\frac{86400 * C D D}{R_{w, t} * E E R} \\
& E_{\text {year }, \text { roof }}=\frac{86400 * C D D}{R_{r, t} * E E R}
\end{aligned}
$$


Where EER is the energy efficiency ratio of the air conditioner. In case of an insulated thermal mass, a layer of insulated material is added which decreases overall HTC and hence lesser cooling energy is required for a building with insulated wall and roof. Annual cooling energy required for such buildings can be given by following equations-

$$
\begin{aligned}
& E_{\text {year, wall }}=\frac{86400 * C D D}{\left(R_{w, t}+R_{\text {ins }}\right) * E E R} \\
& E_{\text {year,roof }}=\frac{86400 * C D D}{\left(R_{r, t}+R_{\text {ins }}\right) * E E R}
\end{aligned}
$$

(7)

Where $R_{\text {ins }}$ is the thermal resistance of added insulation material layer on the wall and roof. If $\mathrm{x}$ and $\mathrm{k}$ is the thickness of the insulation layer and thermal conductivity, $R_{\text {ins }}$ can be given as-

$$
R_{\text {ins }}=\frac{x}{k}
$$

Equation (8) signifies that resistance offered by the insulation material increases with the thickness of the layer. However, the cost of the insulation is also increased with the thickness. Therefore, a cost based model is selected to obtain optimum insulation thickness for which net cost saving can be maximized. A cooling energy cost saving function can be derived as follows-

$$
C_{n e t}=\left(C_{1}-C_{2}\right)-C_{i} * x
$$

Where $C_{n e t}$ is the net cost of cooling energy saved per unit area of the thermal mass, $C_{1}$ is the cooling energy cost for a non-insulated thermal mass per $\mathrm{m}^{2}, \mathrm{C}_{2}$ is the cooling energy cost for an insulated thermal mass per $\mathrm{m}^{2}, \mathrm{C}_{\mathrm{i}}$ is the insulation cost per $\mathrm{m}^{3}$ of insulation and $\mathrm{x}$ is the insulation layer thickness. Cooling energy cost of non-insulated and insulated wall can be obtained as follows-

$$
\begin{aligned}
& C_{1}=\frac{86400 * C D D * C_{e} * P W F}{R_{w, t} * E E R} \\
& C_{2}=\frac{86400 * C D D^{*} C_{e} * P W F}{\left(R_{w, t}+R_{i n s}\right) * E E R} \\
& C_{n e t}=\left(\begin{array}{c}
\frac{86400 * C D D^{*} C_{e} * P W F}{R_{w, t} * E E R} \\
-\frac{86400 * C D D^{*} C_{e} * P W F}{\left(R_{w, t}+\frac{x}{k}\right) * E E R}
\end{array}\right)-C_{i}^{* x}
\end{aligned}
$$

Where Ce is the per unit cost of electricity and PWF is the present worth factor, a term used for life cycle cost estimation and is derived by the following relations [13]-

$$
\begin{aligned}
& P W F=\frac{(1+r)^{N}-1}{r *(1+r)^{N}} \\
& \text { If } i>g ; \quad r=\frac{i-g}{1+g}
\end{aligned}
$$

$$
\text { If } i<g ; \quad r=\frac{g-i}{1+g}
$$

Where $\mathrm{N}$ is the estimated life of insulation, $\mathrm{i}$ and $\mathrm{g}$ are the interest rate and inflation rate respectively. In the (12), $C_{t}$ is the function of insulation thickness x. To determine OIT, first and second derivative of $C_{t}$ with respect to thickness $x$ is obtained. Second derivative turned out as negative which indicates that by equating the first derivative to zero, we can determine the thickness at which $\mathrm{C}_{\mathrm{t}}$ is maximum. Therefore, using this principle OIT for wall obtained by the first derivative of (12) as-

$$
x_{\text {opt }}=293.94 *\left(\frac{C D D^{*} C_{e} * P W F * k}{C_{i} * E E R}\right)^{\frac{1}{2}}-k * R_{w, t}
$$

Similarly, in case of roof OIT can be gives as-

$$
x_{o p t}=293.94 *\left(\frac{C D D * C_{e} * P W F * k}{C_{i} * E E R}\right)^{\frac{1}{2}}-k * R_{r, t}
$$

Equation (16) and (17) can be used to determine the required OIT of an insulation material with conductivity $\mathrm{k}$ and cost $C_{i}$ per $\mathrm{m}^{3}$ for wall and roof in different household locations having distinct CDD, price of electricity and EER of air conditioner. In this work, OIT for wall and roof have been derived for households located in three climate regions of India, namely warm-humid, hot-dry and composite climate zones by selecting three representative cities Mumbai, Jodhpur and Lucknow in the respective zone. Electricity saving potential in an insulated envelop and associated life cycle cost saving analysis is carried out considering the application of four commercial insulation materials namely, expanded polystyrene, fiberglass, polyurethane foam and extruded polystyrene. Following properties (Table I and Table II) of a business as usual (BAU) constructed residential building and insulation materials have been considered-

Table- I: Thickness of individual construction layer in meter $(\mathrm{m})$ from outside to inside

\begin{tabular}{|c|c|c|c|c|}
\hline Component & $\begin{array}{c}\text { Cement } \\
\text { Plaster } \\
\text { (External) }\end{array}$ & RCC & Brick & $\begin{array}{c}\text { Cement } \\
\text { Plaster } \\
\text { (Internal) }\end{array}$ \\
\hline Roof & 0.05 & 0.125 & - & 0.025 \\
\hline Wall & 0.018 & - & 0.230 & 0.025 \\
\hline
\end{tabular}


Table- II: Properties of structural components and insulation materials [14]

\begin{tabular}{|c|c|c|c|c|}
\hline $\begin{array}{c}\text { Structural } \\
\text { Component }\end{array}$ & $\begin{array}{c}\text { Density } \\
\left(\mathrm{kg} / \mathrm{m}^{3}\right)\end{array}$ & $\begin{array}{c}\text { Conductivity } \\
\left(\mathrm{W} / \mathrm{m}-{ }^{-} \mathrm{K}\right)\end{array}$ & $\begin{array}{c}\text { Specific } \\
\text { heat } \\
(\mathrm{kJ} / \\
\left.\mathrm{kg}-{ }^{-} \mathrm{K}\right)\end{array}$ & $\begin{array}{c}\text { Cost } \\
\left(\mathrm{INR} / \mathrm{m}^{3}\right)\end{array}$ \\
\hline Cement Plaster & 1760 & 0.723 & 1 & - \\
\hline Brick & 1700 & 0.84 & 0.8 & - \\
\hline RCC & 2300 & 1.59 & 1 & - \\
\hline $\begin{array}{c}\text { Insulation } \\
\text { Material }\end{array}$ & 24 & 0.035 & 1.34 & 7200 \\
\hline $\begin{array}{c}\text { Expanded } \\
\text { Polystyrene(EPS) }\end{array}$ & 32 & 0.032 & 0.81 & 10800 \\
\hline $\begin{array}{c}\text { Extruded } \\
\text { polystyrene(XPS) }\end{array}$ & 36 & 0.027 & 0.82 & 15600 \\
\hline $\begin{array}{c}\text { Polyurethane } \\
\text { Foam (PUF) }\end{array}$ & 36 & \multicolumn{1}{|c|}{} \\
\hline
\end{tabular}

Thermal resistance of the non-insulated wall and roof were obtained by referring relevant data from the Tables 1 and 2 as $0.497 \mathrm{~m} 2-{ }^{\circ} \mathrm{K} / \mathrm{W}$ and $0.337 \mathrm{~m} 2-{ }^{\circ} \mathrm{K} / \mathrm{W}$, respectively. taken as $6 \%$ and $5 \%$ respectively. CDD is obtained from the web source (www.degreedays.net) for the three cities. Default design temperature is considered as $25^{\circ} \mathrm{C}$ and average EER of the air conditioner is taken as 3.1. Electricity cost has been taken from respective electricity service providers in the three cities.

\section{RESULTS}

As discussed in the previous section, effect of applying four types of insulation materials in a business as usual to be numerically assessed in this study. The desired outcomes of this investigation are as follows:

- Optimum insulation thickness required for roof and external wall in three representative cities using four types of insulation material at a specific design temperature

- Effect of baseline temperature on optimum insulation thickness

- Determination of annual electricity saving potential

- Determination of lifecycle cost saving

At first, effect of adding different insulation materials on roof and external on the cooling energy cost and total cost was obtained for the three cities at the design temperature $25^{\circ} \mathrm{C}$. For instance, Fig. 2 shows the effect of adding EPS insulation on external wall at the incremental thickness of 5 $\mathrm{mm}$ in the city Mumbai.

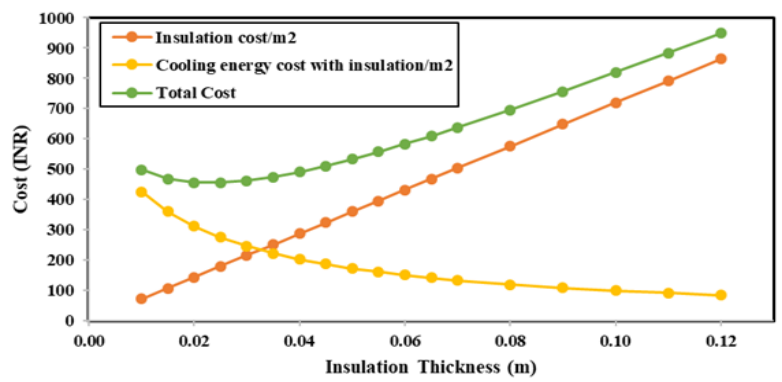

Fig. 2 Space cooling energy cost using expanded polystyrene insulation on external walls for the city Mumbai In the calculations, interest rate and inflation rate have been (BAU) constructed building components (wall and roof) is

Further, OIT for wall and roof at various design temperature using different insulation material was obtained for three cities using (16) and (17). Fig. 3, 4 and 5 shows the optimum insulation thickness required for the wall at various design temperatures for the city Mumbai, Lucknow and Jodhpur respectively. These figures clearly indicates that OIT increases as the design temperature decreases. It is essentially due to higher CDD at low design temperatures. It was also observed that required OIT for roof is more than wall for all the cases. Such a case has been represented for the city Jodhpur in the Fig. 6. It can be explained by the fact that BAU constructed roof has higher overall HTC compared to wall.

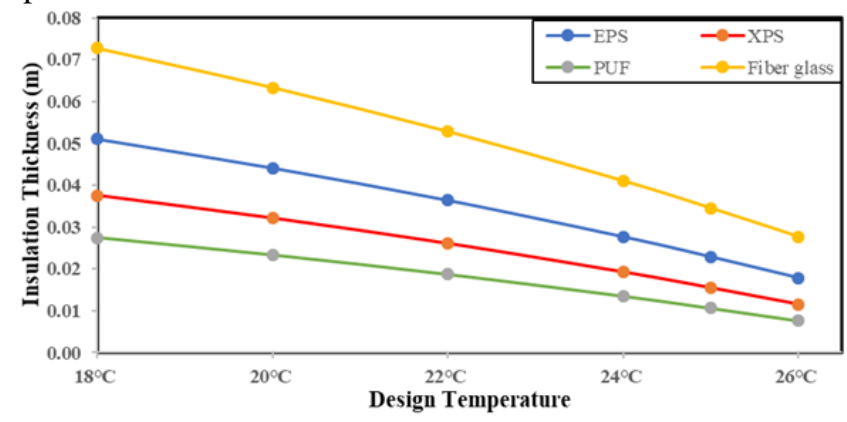

Fig. 3 Variation in optimum insulation thicknesses with cooling design temperature for external wall for the city Mumbai

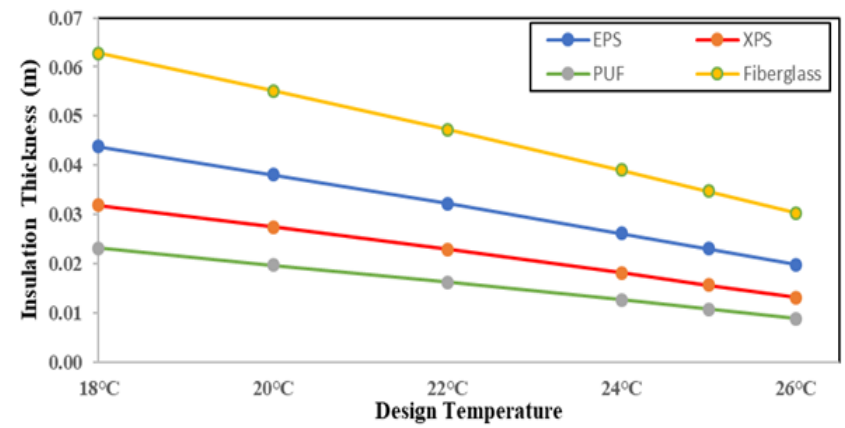

Fig. 4 Variation in optimum insulation thicknesses with cooling design temperature for external wall for the city Lucknow.

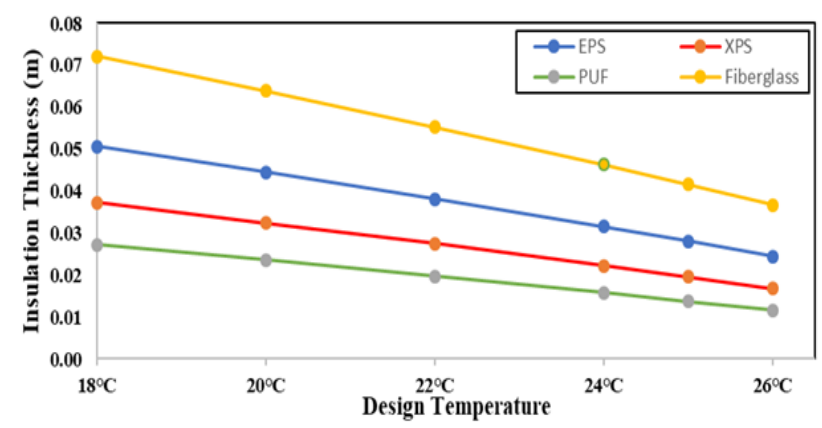

Fig. 5 Variation in optimum insulation thicknesses with cooling design temperature for external wall for the city Jodhpur.

Published By:

Blue Eyes Intelligence Engineering 




Fig. 6 Variation in optimum insulation thicknesses with cooling design temperature for roof for the city Jodhpur.

Amongst four insulation materials analyzed in this work, fiberglass requires the maximum OIT whereas PUF requires minimum OIT. Also, Jodhpur city require more i0nsulation compared to other two cities. Effect of insulated building on electricity consumption and LCC was also determined for the three cities. Fig. 7 shows the comparison of electricity consumption per unit area of a wall in an insulated and noninsulated building at the design temperature $25^{\circ} \mathrm{C}$. Similar investigations were carried out at various design temperatures $\left(18^{\circ} \mathrm{C}\right.$ to $\left.26^{\circ} \mathrm{C}\right)$ for wall as well as for roof for all the three cities. It was concluded that their exist electricity conservation potential of $9 \mathrm{kWh}$ to $16 \mathrm{kWh}$ per unit wall area, whereas in case of roof it varies from $18 \mathrm{kWh}$ to $28 \mathrm{kWh}$ per unit area per year at the design temperature $25^{\circ} \mathrm{C}$. Next, life cycle cost saving estimation was performed for the three cities as shown in the Fig. 8.

\section{CONCLUSION}

In this work, OIT and associated electricity saving potential has been estimated for the residential buildings in three climate zones of India. It was observed that at the design temperature $25^{\circ} \mathrm{C}$, annual electricity saving potential in retrofitted wall per $\mathrm{m} 2$ varies from $9 \mathrm{kWh}$ to $16 \mathrm{kWh}$, whereas in case of roof it varies from $18 \mathrm{kWh}$ to $28 \mathrm{kWh}$ per unit area per year. Fiberglass is observed as the most cost effective insulation material, considering life cycle performance of the insulation material for all the climate zones. However, maximum electricity conservation potential exist in the polyurethane material. Thereby, there exist significant electricity saving potential using insulation in the existing Indian households.

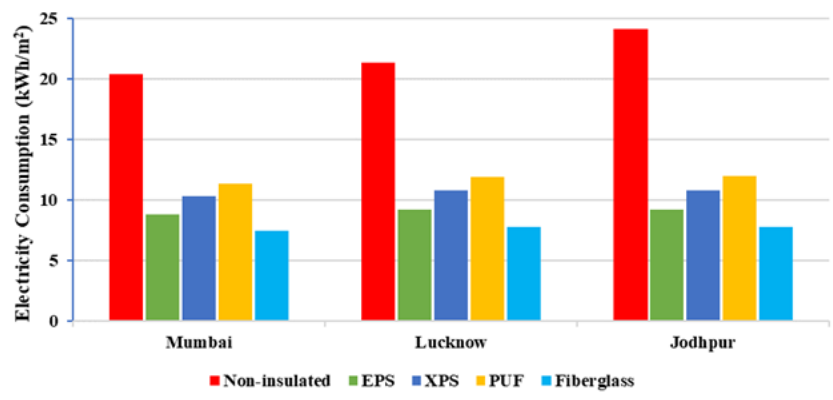

Fig. 7 Electricity consumption in the building for insulated and non-insulated per unit wall area per annum at temperature $25^{\circ} \mathrm{C}$

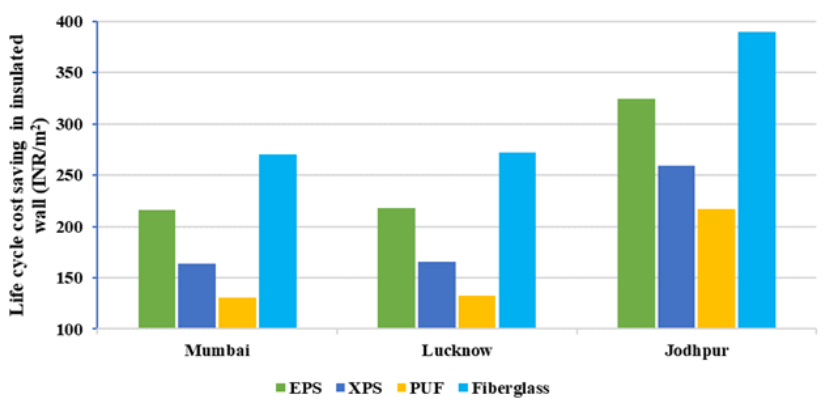

Fig. 8 Life cycle cost saving estimation for per unit insulated wall area at design temperature $25^{\circ} \mathrm{C}$.

\section{REFERENCES}

1. Central Electricity Authority (CEA), Government of India http://www.cea.nic.in/reports/others/planning/pdm/growt h_2018.pdf, Accessed on 28/04/2019.

2. Isaac, M., and Van Vuuren, D. P., "Modeling global residential sector energy demand for heating and air conditioning in the context of climate change", in Energy Policy, 2009, vol.37, pp. 507-521.

3. Abhyankar, N., Shah, N., Park, W. Y., \& Phadke, A. A., "Accelerating Energy efficiency improvements in room air conditioners in India: Potential, costs-benefits, and policies" in Lawrence Berkeley National Laboratory, 2017.

4. Singh, J., Mantha, S. S., \& Phalle, V. M., "Characterizing domestic electricity consumption in the Indian urban household sector", in Energy and Buildings, 2018, vol. 170, pp. 74-82.

5. India insulation forum, available at www.slideshare.net/KrithikaN2/k-k-mitra1. Accessed on 28/04/2019.

6. Çomakl1, K., \& Yüksel, B., "Optimum insulation thickness of external walls for energy saving", in Applied Thermal Engineering, 2003, vol. 23, pp. 473-479.

7. Dombayc1, Ö. A., Gölcü, M., \& Pancar, Y., "Optimization of insulation thickness for external walls using different energy-sources" in Applied Energy, 2006, vol. 83, pp. 921-928.

8. Hasan, A., "Optimizing insulation thickness for buildings using life cycle cost", in Applied Energy, 1999, vol. 63, pp. 115-124.

9. Shanmuga Sundaram, A., \& Bhaskaran, A., "Optimum insulation thickness of walls for energy-saving in hot regions of India", in International Journal of Sustainable Energy, 2014, vol. 33, pp. 213-226.

10. Kumar, A., \& Suman, B. M., "Experimental evaluation of insulation materials for walls and roofs and their impact on indoor thermal comfort under composite climate", in Building and Environment, 2013, vol. 59, pp. 635-643.

11. Tulsyan, A., Dhaka, S., Mathur, J., \& Yadav, J. V., "Potential of energy savings through implementation of Energy Conservation Building Code in Jaipur city, India”, in Energy and Buildings, 2013, vol. 58, pp. 123130.

12. Chedwal, R., Mathur, J., Agarwal, G. D., \& Dhaka, S., "Energy saving potential through Energy Conservation Building Code and advance energy efficiency measures in hotel buildings of Jaipur City, India" in Energy and Buildings, 2015, vol. 92, pp. 282-295. 
13. Yildiz, I., \& Sosaoglu, B., "Spatial distributions of heating, cooling, and industrial degree-days in Turkey", in Theoretical and Applied Climatology, 2007, vol. 90, pp. 249-261.

14. Bansal, N. K., \& Bhattacharya, A., "Parametric equations for energy and load estimations for buildings in India", in Applied Thermal Engineering, 2009, vol. 29, pp. 37103715 .

\section{AUTHORS PROFILE}

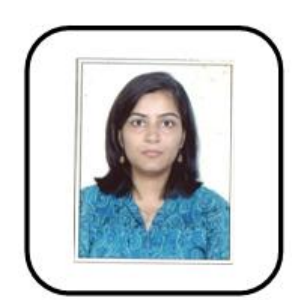

Jaya Goyal is a Ph.D research scholar in the department of Mechanical Engineering at Veermata Jijabai Technological Institute (VJTI), Mumbai, India. She did her M.Tech. in Machine Design from (VJTI) in the year 2015. She has presented papers in many International conferences and published the research papers in International journals. Her building and sustainable energy systems. area of interest are development of green

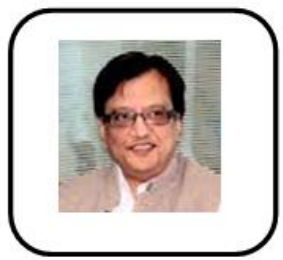

Dr. Shankar S. Mantha is emeritus professor and former chairman of All India Centre for Technical Education (AICTE). He worked as professor of robotics and $\mathrm{CAD} / \mathrm{CAM}$ in the department of Mechanical Engineering and superannuated in the year 2016. He holds a Ph.D degree in combustion modelling from Mumbai University, India. Dr. S.S. Mantha has been awarded D. Sc (h.c.) by VTU, Karnataka in March 2012



Dr. Vikas M. Phalle is associate professor in the department of Mechanical Engineering at Veermata Jijabai Technological Institute, Mumbai, India. He holds a Ph.D degree in Mechanical Engineering from Indian Institute of Technology, Roorkee, India. She has presented papers in many International conferences and published the research papers in International journals. 